\title{
The Journal is dead, long live the Journal
}

Danny Kingsley, On the Horizon, special issue "The Fate of the Academic Journal”

\section{Abstract}

\section{Purpose}

To argue the traditional scholarly journal system is outdated and in need of revamp, and new internet technologies provide opportunities for change unavailable until now.

\section{Design/methodology/approach}

The four functions of the scholarly journal; registration, awareness, certification and archiving are discussed in turn and alternative ways of undertaking those functions are explored. Barriers to change and ways to overcome these barriers are addressed.

\section{Findings}

The functions of registration and certification are already met with an open peer review system in place for some high profile journals.

Recently developed searching and browsing facilities give academics access to a greater proportion of scholarly literature, providing a more efficient awareness function than traditional journals. The function of archiving is not being adequately addressed by commercial publishers, and the steps being taken by institutional repositories to that end are more sustainable. 
The fundamental tenet of science as part of the public domain is being eroded by commercial gain, and a move away from the traditional scholarly system can reverse that trend.

Barriers to change are; the publisher's commercial imperative to maintain the status quo, the academy's reluctance to change, and the reward system. However, recently both publishers and academics have demonstrated a willingness to try new systems. The barrier of institutional reliance on metrics poses the greatest threat to change.

\section{Originality/value}

This paper builds on an historical background of arguments dating back to 1926, but uses up-to-date examples of ways publishers are moving towards change. The paper will inspire debate in the scholarly community.

\section{Autobiographical note:}

Danny Abigail Kingsley, PhD Candidate, Australian National University, danny.kingsley@anu.edu.au, Centre for the Public Awareness of Science, Physics Link Building [38A], Australian National University, Canberra ACT 0200

\section{Keywords}

Scholarly communication, journal, institutional repository, peer review, sustainability, reward

\section{Paper classification}

Conceptual paper 


\section{Introduction}

The internet has opened up new possibilities for publication that were only dreamed of 20 years ago. The traditional academic journal with its title in bound volumes on a library shelf is already redundant. However, the concept of the journal will survive, maintaining the elements of a recognised editorial board, and peer-reviewed articles. What form these future 'journals' will take will depend largely on technological developments over the next few years, but already we are seeing aspects of the traditional journal being undertaken in unconventional ways.

This article focuses on scientific communication, which primarily uses journal articles or conference proceedings as its official output. This is in contrast to some social sciences and humanities disciplines, with an output that also includes monographs, performances or exhibitions. A journal is defined here as a periodical publication, either in print or (increasingly) electronic format. Articles are submitted for peer review, reviewed and edited before being formatted and published. Journals are usually published by either a commercial publisher (such as the one in which this paper appears) or by a learned society (scholarly association).

\section{Historical perspective}

This paper is not the first to suggest changes to the scholarly communication system, it builds on a rich history. There has been dissatisfaction with the journal system for decades. In 1960, delays in publication, restrictions on article length with the necessary omission of relevant supporting data, high costs preventing full coverage of any 
field and the time 'wasted' on editing and reviewing were all perceived to be problems with the system. (Phelps and Herlin, 1960)

The suggestion that the journal be substituted with individual papers as the primary unit of distribution was first made in 1926. A 1933 proposal suggested replacing journals with an international publishing house, a 'Scientific Information Institute', to take over all existing scientific publishing and bibliography, where authors would submit to the centre. A variation on this theme was the idea of a central editorial bureau of scientific experts to review, correct, edit and verify papers. (Phelps and Herlin, 1960) This followed in turn the concept for central depositories of background material (what we call grey literature today), which could be "mimeographed or otherwise duplicated and placed in certain repositories". (Allen, 1922)

However, an UNESCO review of 1960 concluded that "the case for replacement of the scientific periodical by a system of separates distributed either from a central depository or by individual societies has not been proved." (Phelps and Herlin, 1960)

Harnad was an early, and continues to be a tireless, campaigner for change to scholarly communication. He first came to prominence in this field with his 'subversive proposal', suggesting a radically decentralised scholarly publishing model, in which scholars selfpublish their works, which then may or may not be peer reviewed. (Brent, 1995) Odlyzko proposed in 1996 that electronic journals could exist as collections of unpackaged, but potentially refereed documents in a central server. The inspiration for this was Paul 
Ginsparg's working article server' at Los Alamos, begun in 1991.

(Odlyzko, 1996) This was followed by the prediction of an "universal, Internet-based, bibliographic and citation database". (Cameron, 1997) The concept of an 'electronic aggregator' was put forward in 1999, consisting of a collection of self-published papers. (Kling and McKim, 1999)

Current complaints about journals do not differ significantly from those raised in 1960. And while the roles of certification and peer review have not changed much since the 1960's, the journal system has in other ways undergone a massive upheaval. Science and therefore scientific publishing boomed after the 1950's, when commercial publishers became an ever-increasing presence in the market. What has changed in this time is the publisher's role, and the subsequent escalating subscription costs and the manipulation of the system. (Bergstrom, 2001)

\section{The functions of the journal}

The formal scientific communication process has been described in terms of four functions: registration, awareness, certification and archive. (Roosendaal and Geurts, 1997) Journal publication currently fulfils these functions, but this paper argues they can be met by other means.

Over the past 400 years, the publishing function of journals has changed from a method of communication to a career tool. Early journals were publications of works-in-progress, and subsequent monographs were considered the final stage of the published work. 
Over time, the journal has become for many disciplines the ultimate version of a scholar's work, "thus the fundamental purpose of the journal has changed. In no small measure, scholarly communication has changed to become publishing." (Peek, 1996) [p5]

Today, few (if any) science scholars use journal articles as a primary communication tool. Recreating print journals online does not take advantage of technology. Delays in the peer review process mean that the ideas presented in an article are known to members of a scholarly field well before publication through conference presentations, email lists, deposited pre-prints, mailgroups, weblogs and other forms of modern communication. These tools are being developed to take advantage of needs in the marketplace not being met by traditional publishers. (Esposito, 2004) In a time of instant messaging (for younger researchers), a 12 month-plus delay is interminable. "What does 'published' mean, exactly, for a paper that has already been downloaded thousands of times, whose summarized contents have been read by many more thousands...? Whatever the economics journals are doing, 'publishing' is hardly an accurate description." (Deaton, 2006) [p6]

It is reasonable to ask, given the myriad of possibilities technology offers, why we persist with a journal system at all. In order to answer this we need to understand the dual roles of a researcher. The researcher wears two hats, that of author and that of reader, and the scholarly communication system of journal publication means different things depending on the hat in question. (Guedon, 2001) The name, status and impact factor of a journal are very important to an 
author - with implications for assessment, tenure and grant applications. In this context the journal fulfils the roles of registration and certification. The reader, on the other hand, is not greatly concerned with the journal except that it contains an article they wish to read (unless they cannot obtain access to it). "Authors are focused on journals, usually particular journals, while, as readers, the same researchers [are] focused on large collections of articles and journals that they wished to browse. More worryingly (for publishers), researchers as authors want to publish more, while as readers they want to read less." (Mabe and Amin, 2002) [pp150-151]

If we are to move to a new system of scholarly communication, it is important to incorporate those necessary elements of the old. Authors have specific requirements of the journal system: "they want the ability to target a very specific group of key readers... and they want the imprimatur of quality and integrity that a good peer-reviewed, high-impact title can offer, together with reasonable levels of publisher service". (Rowlands et al., 2004) [p273] In other words, authors need the communication system to take care of awareness and certification. To a reader of a paper, however, the only factor is the quality of the content, which is verified by peer review, and the journal name (or brand, to use a marketing term). In this instance, certification is the primary function played by the journal.

\section{Alternative ways to perform journal functions}

This section will examine each of the four functions, registration, certification, awareness and archiving in turn, discussing the journal's 
role in each and describing alternative ways these functions can be addressed.

\section{Registration}

Registration, establishing intellectual priority, is achieved by publishing articles in journals. Priority is conferred to an individual or group on the date of publication, and this is problematic considering the often substantial period of time between submission of an article and its publication. (Torgerson et al., 2005) If two authors were to write similar articles, currently the arbitrary nature of the length of the review process will determine which author is given priority. Placing the pre-review articles online for open peer review eliminates this artificial constraint on accurate registration of ideas by identifying the author of the idea at the time of submission. A system of peer review occurring openly using the internet could act in the registration role.

While this may be a challenging concept for some, several experiments are already underway. During the development of this paper, one of the highest impact journals, Nature, has been conducting a trialii, in which papers undergoing individual peer review are concurrently posted on the web for other scientists to comment, and these online comments are taken into consideration by the reviewers.

There may be unplanned advantages of such a system. The public nature of the pre-refereed article may encourage authors to take more care when writing their articles. On example is Atmospheric Chemistry and Physics ${ }^{i i i}$, which is currently making peer-review open 
to reviewers and the public. Comments are kept online permanently and they are citable. The public peer review and interactive discussion appears to deter authors from submitting low-quality manuscripts. (Koop and Poschl, 2006)

\section{Awareness}

Considering awareness, the questions are; what are people reading and how do these readers currently find their information? In the days of printed journals, it was difficult to measure what literature was actually being used. Libraries relied on call slips and counts by shelvers to determine use of their collections. Traditionally the readership of articles has been tracked by citation count, a numerical analysis of the number of times other articles cite a particular article. Modern technology, however, opens up interesting alternatives to this, such as counting the number of times an electronic article is downloaded, meaning "scholars can have a much more accurate picture of what is being read than what is offered by the traditional reliance on citations." (Galvin, 2004)

These different approaches to measuring readership invite formal comparison. One study directly comparing these two methods in the same journal produced some interesting results. (Coats, 2005) There was no overlap between the top 10 articles downloaded from this journal and the top 10 cited articles over the previous 12 month period. Coats et al made the observation that "an author may be tempted to cite the article a referee may expect rather than the paper the author really needs to read or depend on". [p124] 
Today, databases of published material are being comprehensively searched. A deep log analysis of the 'fingerprints' left behind by readers searching the OHIOLink digital library showed that $99 \%$ of journals available in a given month were viewed in that month.

(Nicholas and Huntington, 2006) It is unlikely the same claim could have been made of paper journals in the same library twenty years ago. That said, downloads are equally unsatisfactory as an indication an article has been read. Online researchers read only the abstracts of longer articles but shorter articles are read in full. "In fact, a lot of squirreling away does go on in cyberspace, where people are simply gathering articles that they hope to have time to read later or might need some time in the future, but probably never do.... In other words if you actually wanted people to read something online, then and there, make it short." (Nicholas and Huntington, 2006) [p50]

Despite technological advances, there is still no satisfactory method of determining what articles are being read, but there is evidence to show that the articles people are reading are increasingly sourced as separates rather than as part of a journal. (Tenopir et al., 2003) The journal's importance in scholarship (to the reader) is decreasing. "Scientific information is exchanged in a multi-tiered manner, and those myriad other channels render the scientific manuscript optional, if not obsolete. . . Often the journal article, the bedrock of peerreviewed scientific knowledge, is the last information source consulted." (Seringhaus and Gerstein, 2006)

Increasingly, researchers are looking at individual articles. "With evolution toward advanced systems, scientists seem to browse 
journals less often and spend more time searching online. It may be that scientists move away from traditional browsing of journals as electronic access to secondary databases and to aggregated full texts becomes more ubiquitous." This is reflected in the finding that in 2002 over $80 \%$ of the separate copies read came from either a preprint or an archive, where previously these had been obtained from colleagues. (Tenopir et al., 2003)

An early argument against a separates system was the subsequent loss of casual reading or browsing, as, "it is possible that the haphazard reading of scientists is a significant factor in scientific progress." (Phelps and Herlin, 1960) [p68] This method of finding articles (for example, by scanning the contents tables of journals) is often referred to as the 'serendipity' of research. However, far from hindering the surprise unearthing of articles, modern searching tools are comprehensively replacing the old methods of 'browsing'. Indeed the same term is used for online searching on the Web. Unfortunately there are currently substantial holes in the coverage of available search engines, as demonstrated clearly by Willinsky in an appendix to his book The Access Principle, (Willinksy, 2006) and he describes the 'One Great Scholarly Search Engine' as a golden chalice for researchers and librarians worldwide.

\section{Certification}

Certification is the only role journals play for both readers and authors, and the majority of this work such as peer review, editing, and paper selection is undertaken by the academy for the publishers, usually for little or no compensation. There are advantages to those 
doing the work, not least potentially favourable consideration when submitting their own paper to the journal at a later date, but there is no compelling reason for academics to continue supporting this status quo. "The weakness in the publishers' position is that all they own is the journal name. Editors and editorial boards are not indentured servants." (Bergstrom, 2001)

Peer review must remain in any new model. In the era of ever increasing material, a certification system is required more urgently than ever. There is argument that peer review has two distinct functions; to provide feedback to the author of a paper in order to improve the paper, and to determine the quality of a paper (and its appropriateness for a particular journal). (Sandewall, 2006) The feedback function can be addressed in an open forum as discussed in the Registration section, above. The quality functions allows readers to make predetermined judgements about a paper prior to reading it, so the journal, if nothing else, gives an effective ranking to a paper. This role, that of defining the quality threshold, should continue under the new system, but with different methodology - for example a star rating, instead of a branded journal.

There are several examples of alternative certification in new publishing systems. The Berkeley Electronic Press, or bepress ${ }^{i v}$, allows authors to submit to a central point for assessment so the refereeing only occurs once. "A pre-print does not need to be resubmitted to multiple rejecting journals of decreasing quality to find its appropriate public venue" (Rodriguez et al., 2006) [p151] This is 
more efficient because it uses only one set of referees to publish a paper.

There have been calls for a collective publishing system, where academics must be members of the collective in order to publish through it and a requirement of this membership is a contribution to the publishing process. This contribution could be in various forms such as refereeing, editing, or typesetting. (Fitzpatrick, 2006). This idea has merit, however while academics are certainly the best people to undertake refereeing, in relation to copyediting and typesetting, why not leave it to those that are the experts publishers?

\section{Archiving}

It is the function of archiving that will, perhaps counter-intuitively, be best served by a move away from the journal system. Paper versions of journals were distributed worldwide, so there were copies of the same journal issue in separate locations. This meant libraries acted as archives by default ${ }^{\vee}$. Now that many libraries only subscribe to the electronic version of journals, and some journals do not actually have a print version, this automatic process is not occurring. The final function of scholarly communication, archiving, is thus threatened.

From the problems presented by articles saved in commercial software programs such as Microsoft Word, which are not suitable for long-term storage and need to be converted into an archival format for preservation (Barnes, 2006) through to the lack of commitment by governments and institutions (at least in Australia) to the long-term 
protection of data and online material, (Buchhorn and McNamara, 2006) archiving, or more accurately, digital sustainability is a Pandora's box of issues. While archiving is considered to be one of the four fundamental functions of scholarly communication, very little serious attention has been focused on this increasingly complex issue.

There is an unstated assumption that publishers are taking on this role, but little discussion of the situation. "The scholarly community is increasingly suspicious that electronic publishers are not taking on the responsibility of archiving indefinitely. Indeed, when web journals with their remote and possibly unstable links entered the picture, archiving became a major problem. Must libraries print or store electronically the full text and all linked material included at the time of publication in order to preserve the intellectual record?" (Galvin, 2004) The commercial reality is there is far more income to be derived by publishers from new articles, than from the potentially very expensive job of ensuring long term digital sustainability of old ones.

Facilitating a move to a system of separates is the increasing number of institutional repositories worldwide. These digital spaces are often built with open source software by institutional libraries and have dual roles. One is as a future digital library for current holdings and future digitisation of other, more ephemeral artefacts. The other role more relevant to this discussion is as a repository for academics to deposit pre- and post-prints of articles. Almost all institutional repositories have OAI-PMH ${ }^{\text {vi }}$ compatibility, a commitment to long-term preservation and facilities for recording the details of input, so are 
able to fulfil the scholarly communication functions of awareness, archive and registration respectively. The issue of certification, a function currently being undertaken at no cost by the scholarly community in the form of peer review, could continue with amended administration.

While advocates of the open access movement have expressed frustration at the emphasis by libraries on the preservation role of digital repositories ${ }^{\text {vii }}$, this may support the revolution of the journal. Ongoing archiving is a real problem that needs to be addressed, and not by publishers. Governments worldwide are beginning to look at digital sustainability as more digital repositories are established. The future of archiving is safer in the hands of institutions or governments, than at the mercy of commercial imperatives.

\section{Advantages of changing the system}

Some would argue that the system 'works' so why consider changing it? The answer is another question: works for whom? By writing, refereeing and editing articles, academics receive professional recognition of their research. But the real beneficiaries of the current system are commercial publishers who have massive profits (Bergstrom, 2001), and institutions, which are increasingly using metric counts to make tenure and grant decisions.

Research is a public activity, with 'communism', an extended sense of common ownership of goods, an integral element of the scientific ethos. "The institutional conception of science as part of the public domain is linked with the imperative for communication of findings." 
(Merton, 1973) [p274] This communication has traditionally been by writing and publishing academic articles. However, by restricting people's access to that knowledge, the fundamental basis of the activity of science is being stemmed for commercial gain.

When we look at the total life cycle of the journal, most of the cost is incurred in the undertaking of the actual research. A large portion of the cost of publishing (such as peer review) is also borne by universities and libraries. (Houghton et al., 2006) But, "because of the commercial interests of one group of stakeholders, the journal publishers, which incur a very small fraction of the total life-cycle cost, the access to scientific publications is highly restricted and expensive and the process as a whole is highly inefficient". (Tenopir and King, 2001) [p8]

The problem with maintaining the journal structure, even in an open access 'author-pays' system is principally one of cost. Even with an open access journal structure the costs will keep rising because the author has a vested interest in being published, and therefore will be prepared to invest in more and more 'value adds' that open access publishers could provide. These include domain names, blogging software, metatagging tools and network links. "OA, through the range of new services it will provide, will increase the overall cost of scholarly communication". (Esposito, 2004)

Another important argument for a move away from a traditional journal system towards one of electronically available separates is the increase in use of the articles. There is now substantial evidence to 
show that articles that are made freely available online have a far greater impact than those languishing behind toll barriers. (Hitchcock, 2006) While there is some argument over the most beneficial route to open access - publication in an open access or hybrid journal, or depositing an article in a repository (Eysenbach, 2006), the relevant point is that scholars are 'voting with their feet'. If it is freely available they will use it. The intriguing possibility is that by placing material online in this way, articles may once again actually be used as a communication tool rather than simply a check box for the author's next grant application

\section{Barriers to change}

The journal has changed its role since inception, from a communication tool to a communication system tool. Researchers now use other methods to communicate their findings, but still rely on the journal article as a way to further their careers. Any analysis such as this one must consider what will prevent a change to the current journal system. There are some groups who have a strong vested interest in maintaining the status quo.

Perhaps surprisingly to some, I see that a separates system would not eliminate the need for publishers. Some roles, such as professional copy editing, layout and design, technical support and so on will need to be undertaken, and there is no reason these services cannot attract a fee. The publisher's role would thus require a substantial change of focus, and a loosening of the control they currently have. More enlightened publishing professionals may be 
able to see that the future requires experiment and change, and will possibly embrace this option, others will go down with the ship.

There are some recent developments that indicate publishers already recognise the need for change. Over $90 \%$ of publishers allow preprints (and in some cases post-prints) of individual articles to be deposited in either an institutional repository or one set up in the

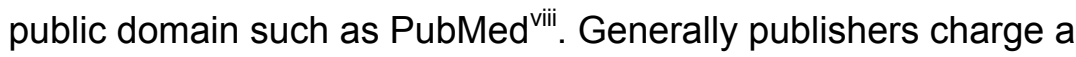
subscription fee for access to journal contents, which is met by libraries in academic institutions. But open access journals use new business models, with some publishers charging a fee per article submitted rather than a subscription. Other commercial publishers work with a combination of the two models, offering open access publication for those who wish to pay for it, with the other articles remaining 'toll access'. ${ }^{\text {ix }}$ Even the Royal Society, which denounced those debating open access as "threatening to hinder rather than promote the exchange of knowledge between researchers", (The Royal Society, 2005) within seven months released a hybrid journal policy, called EXiS Open Choice, allowing authors to pay an up front fee to have their work placed freely online at the time of publication. (The Royal Society, 2006)

In most hybrid option cases the intention is that subscription rates will drop in proportion to the number of articles in a given issue that are freely available. There is little evidence that this is actually occurring, but it may not be published information yet. 
Authors too recognise that change is inevitable. A recent study of over 1200 authors showed almost exactly half ranked 'New forms of electronic-only journals (virtual journals with articles drawn from various sources)' as very important or important in the period to 2008 . Putting this finding in context, this ranked only fifth in a list of eight options. Predictably, the most popular future publishing option was the 'Traditional print + electronic journal'. (Swan and Brown, 2003) However, for any major change to occur in the scholarly communication system, there must be widespread support from those for whom publication is fundamental, the researchers.

The most resistance to change in the scientific publication system is likely to occur in institutional administrations. When Roosendaal and Guerts put forward their theory of four functions of scientific communication, they omitted a fifth - and at this point in the debate, the most important - function, reward. Those researchers who are currently active have always relied on their publication history to help them in tenure and grant applications. This has taken on increasing importance as administrations bring in assessments that rely ever more heavily on easily quantifiable data. University ranking systems such as the Times Higher Education Supplement World University Rankings $^{\mathrm{x}}$ or the Shanghai Jiao Tong World Ranking of Universities ${ }^{\mathrm{xi}}$ have focused publication output onto the relatively small percentage of journals appearing in the Thompson Scientific Journal Citation Reports ${ }^{x i}$.

This situation is becoming problematic for many academics. "We can all start to improve things by toning down our obsession with the 
journal. The most effective change by far would be if the organisations that award grants and manage research programmes were to place much less trust in a quantitative audit that reeks of false precision." (Lawrence, 2003) [p261]

The current reward systems in science (and other areas of academia) are relying more and more heavily on bibliometrics. In the UK, the Research Assessment Exercise is moving towards a metrics based system after the 2008 round and in Australia the proposal for the Research Quality Framework (RQF) (The Expert Advisory Group for the RQF, 2005) can only be managed with an over-reliance on bibliometrics by the assessors due to an unrealistic assessment load. (Steele et al., 2006) This world-wide move towards metric, dubiously qualitative, assessment of work is unfortunately highly regressive and poses the greatest barrier to a revolution of the scholarly communication system.

\section{Conclusion}

The internet offers a vast opportunity for change to the scholarly communication system. This paper has demonstrated that the necessary functions of registration, certification, awareness and archiving can all be addressed equally well, if not better, by alternate systems taking advantage of new technology. The traditional journal with set names, volumes and issues, and its attendant problems of lengthy delays for article publication, high subscription costs and questionable archiving practices is unlikely to continue in a new scholarly communication system. However, the journal concept of an online place where refereed fully searchable articles based on 
thematic ideas can be collated, with hyperlinks to relevant grey literature will remain, albeit in a different form to that currently available.

The barriers to these changes will be the stranglehold publishers have on the communication system, the reluctance of academics to change, and the entanglement of the reward system with the current publishing scenario. However, publishers are already adapting and trialling new ways of delivering services, from new business models offering open access, to the exploration of open, online peer review. Academics have embraced new publishing options, particularly in their role as readers, and as authors they are using the facilities technology provides to increase and improve their communication. The reward system would be better served by more accurate information from deep log analysis of separate refereed articles than by its current reliance on bibliometrics based on citation counts and journal impact factors, and it is up to administrators in large institutions and government departments to recognise this.

The fundamental tenet of research being part of the public domain is being eroded for commercial gain as people's access to the knowledge is increasingly limited by the high subscription costs of commercial publishers. The traditional scholarly communication system no longer supports the communication of findings and only a move towards an adapted journal system can reverse this trend.

\section{Bibliography}

Allen, W. E. (1922) "Repositories for scientific publications", Science, Vol 56, pp. 197-198 
Barnes, I. (2006) "Preservation of Word-Processing Documents," Australian Partnership for Sustainable Repositories, Available from:

http://www.apsr.edu.au/publications/preservation_of_word_pr ocessing_documents.html [Accessed 30 September 2006]

Bergstrom, T. C. (2001) "Free Labor for Costly Journals?", Journal of Economic Perspectives, Vol 15 No 4, pp. 183-198

Brent, D. (1995) "Stevan Harnad's 'Subversive Proposal' Kick-Starting Electronic Scholarship", A Summary and Analysis. EJournal, Vol 5 No 1, Available from:

http://www.ucalgary.ca/ejournal/archive/rachel/v5n1/article.ht $\mathrm{ml}$ [Accessed 30 September 2006]

Buchhorn, M. \& McNamara, P. (2006) "Australian eResearch Sustainability Survey". Canberra, Australian Partnership for Sustainable Repositories and Australian Partnership for Advanced Computing. Available from: http://www.apsr.edu.au

Cameron, R. D. (1997) "A universal citation database as a catalyst for reform in scholarly communication", First Monday, Vol 2 No 4, Available from:

http://www.firstmonday.org/issues/issue2_4/cameron/index.ht $\mathrm{ml}$ [Accessed 30 September 2006]

Coats, A. J. S. (2005) "Top of the charts: Download versus citations in the International Journal of Cardiology", International Journal of Cardiology, Vol 105, pp. 123-125.

Deaton, A. (2006) "American shortcomings: the highs and lows of publication", Royal Economic Society Newsletter, No 135, pp. $5-6$

Esposito, J. J. (2004) "The devil you don't know: The unexpected future of Open Access publishing", First Monday, Vol 9 No 8, Available from:

http://www.firstmonday.org/issues/issue9_8/esposito/index.ht $\mathrm{ml}$ [Accessed 30 September 2006]

Eysenbach, G. (2006) "Citation Advantage of Open Access Articles", PLoS Biology, Vol 4, No 5, pp. 0692-0697, Available from: http://biology.plosjournals.org/perlserv/?request=getdocument\&doi=10.1371/journal.pbio.0040157 [Accessed 30 September 2006]

Fitzpatrick, K. (2006) "On the Importance of the Collective in Electronic Publishing", The Valve - a Literary Organ, Available from:

http://www.thevalve.org/go/valve/article/on_the_importance_of _the_collective_in_electronic_publishing/[Āccessed 30 September 2006]

Galvin, J. (2004) "The Next Step in Scholarly Communication: Is the Traditional Journal Dead?", Electronic Journal of Academic and Special Librarianship, Vol 5 No 1, Available from: http://southernlibrarianship.icaap.org/content/v05n01/galvin_j0 1.htm [Accessed 30 September 2006]

Guedon, J.-C. (2001) "In Oldenburg's Long Shadow: Librarians, Research Scientists, Publishers, and the Control of Scientific Publishing", May 2001 Association of Research Libraries Membership Meeting - 'Creating the Digital Future', Available from: http://www.arl.org/arl/proceedings/138/guedon

[Accessed 30 September 2006] 
Hitchcock, S. (2006) "The effect of open access and downlaods ('hits') on citation impact: a bibliography of studies", OpCit Project, Available from: http://opcit.eprints.org/oacitationbiblio.html [Accessed 30 September 2006]

Houghton, J., Steele, C. \& Sheehan, P. (2006) "Research communication costs in Australia: Emerging opportunities and benefits", Department of Education, Science and Training, Available from:

http://www.dest.gov.au/sectors/research_sector/policies_issue s_reviews/key issues/australian research information infrast ructure_committee/ [Accessed 30 September 2006]

Kling, R. \& McKim, G. (1999) "Scholarly Communication and the Continuum of Electronic Publishing", Journal of the American Society for Information Science, Vol 50 No 10, pp. 890-906

Koop, T. \& Poschl, U. (2006) "Systems: An open, two-stage peerreview journal", Nature Peer Review Debate, Available from: http://www.nature.com/nature/peerreview/debate/nature04988 .html [Accessed 30 September 2006]

Lawrence, P. A. (2003) "The politics of publication", Nature, Vol 422, 259-261

Mabe, M. A. \& Amin, M. (2002) "Dr Jekyll and Dr Hyde: author-reader asymmetries in scholarly publishing", Aslib Proceedings, Vol 54 No 3, 149-157

Merton, R. K. (1973) "The Normative Structure of Science", in Storer, N. W. (Ed.) The Sociology of Science: Theoretical and Empirical Investigations, University of Chicago Press. Chicago

Nicholas, D. \& Huntington, P. (2006) "Electronic journals: are they really used?", Interlending and Document Supply, Vol 34 No 2, pp. $48-50$

Odlyzko, A. M. (1996) "Tragic Loss or Good Riddance? The Impending Demise of Traditional Scholarly Journals". in Peek R. P. \& Newby, G. B. (Eds.) Scholarly Publishing: The Electronic Frontier, MIT Press, Cambridge Massachusetts.

Peek, R. (1996) "Scholarly Publishing, Facing the New Frontiers", in Peek R. P. \& Newby, G. B. (Eds.) Scholarly Publishing: The Electronic Frontier, MIT Press, Cambridge Massachusetts.

Phelps, R. H. \& Herlin, J. P. (1960) "Alternatives to the Scientific Periodical: A report and bibliography", UNESCO Bulletin for Libraries, Vol XIV, pp. 61-75

Rodriguez, M., Bollen, J. \& Sompel, H. V. D. (2006) "The convergence of digital libraries and the peer review process", Journal of Information Science, Vol 32 No 2, pp. 149-159

Roosendaal, H. E. \& Geurts, P. A. T. M. (1997) "Forces and functions in scientific communication: an analysis of their interplay", in Karttunen, M., Holmlund, K \& Hilf, E. R. (Eds.) Cooperative Research Information Systems in Physics. Oldenburg University, Germany.

Rowlands, I., Nicholas, D. \& Huntington, P. (2004) "Scholarly communication in the digital environment: what do author's want?", Learned Publishing, Vol 17 No 4, pp. 261-273

Sandewall, E. (2006) "Systems: Opening up the process", Nature Peer Review Debate, Available from: http://www.nature.com/nature/peerreview/debate/nature04994 .html [Accessed 30 September 2006] 
Seringhaus, M. \& Gerstein, M. (2006) "The Death of the Scientific Paper", The Scientist, Vol 20 No 9, p.25 Available from: http://www.the-scientist.com/article/daily/24465/ [Accessed 30 September 2006]

Steele, C., Butler, L. \& Kingsley, D. (2006) "The Publishing Imperative: the pervasive influence of publication metrics" (in print), Learned Publishing, Vol 19 No 4

Swan, A. \& Brown, S. (2003) "Authors and electronic publishing: what authors want from the new technology", Learned Publishing, Vol 16 No 1, pp. 22-33

Tenopir, C. \& King, D. W. (2001) "Lessons for the Future of Journals", Nature Web Debates: e-access, Available at: http://www.nature.com/nature/debates/eaccess/Articles/tenopir.html [Accessed 30 September 2006]

Tenopir, C., King, D. W., Boyce, P., Grayson, M., Zhang, Y. \& Ebeuen, M. (2003) "Patterns of Journal Use by Scientists through Three Evolutionary Phases", D-Lib Magazine, Vol 9 No 5, Available at: http://webdoc.sub.gwdg.de/edoc/aw/dlib/dlib/may03/king/05king.html [Accessed 30 September 2006]

The Expert Advisory Group for the RQF (2005) "Final advice on the preferred RQF model", Research Quality Framework:

Assessing the quality and impact of research in Australia, Available at:

http://www.dest.gov.au/sectors/research_sector/policies_issue s_reviews/key_issues/research_quality_framework/final_advic e_on_preferred_rqf_model.htm [Accessed 30 September 2006]

The Royal Society (2005) "Royal Society position statement on 'open access'", London, Available at:

http://www.royalsoc.ac.uk/page. asp?id=3882\&printer=1 [Accessed 30 September 2006]

The Royal Society (2006) "Royal Society launches trial of new 'open access' journal service, a press release from the Royal Society", Available at:

http://www.royalsoc.ac.uk/news.asp?id=4838 [Accessed 30 September 2006]

Torgerson, D. J., Adamson, J., Cockayne, S., Dumville, J. \&

Petherick, E. (2005) "Submission to multiple journals: a method of reducing time to publication?", British Medical Journal, Vol 330 No 7486, pp. 305-307, Available at: http://bmj.bmjjournals.com/cgi/content/extract/330/7486/305 [Accessed 30 September 2006]

Willinksy, J. (2006) "The Access Principle: The Case for Open Access to Research and Scholarship", MIT Press, Massacheusetts.

\footnotetext{
'Now run from Cornell University: http://arxiv.org/

ii http://blogs.nature.com/nature/peerreview/trial/

iii http://www.copernicus.org/EGU/acp/

iv http://www.bepress.com/

${ }^{\vee}$ An electronic replica of this system has begin, called Lots of Copies Keep

Stuff Safe - LOCKSS - http://www.lockss.org/lockss/Home
} 
vi Open Archives Initiative Protocol for Metadata Harvesting http://www.openarchives.org/OAl/openarchivesprotocol.html

vii http://www.ecs.soton.ac.uk/ harnad/Hypermail/Amsci/5147.html

viii http://www.sherpa.ac.uk/romeo.php

${ }^{i x}$ These are becoming increasingly popular, with four programs announced in August 2006 alone. The main players are (in order of launch date)

Springer's Open Choice, Blackwell's Online Open, Oxford Open, Elsevier's

Sponsored Article Journals, The Royal Society's ExiS Open Choice, BMJ

Unlocked, Wiley's Funded Access, Cambridge Open, American Physical

Society's Free to Read, and very recently Taylor \& Francis's iOpenAccess.

${ }^{x}$ http://www.thes.co.uk/worldrankings/

xi http://ed.sjtu.edu.cn/ranking.htm

${ }^{x i i}$ http://scientific.thomson.com/products/jcr/ 